\title{
RELATIONSHIP BETWEEN TRANSFORMATIONAL LEADERSHIP AND ORGANIZATIONAL COMMITMENT OF THE CAFÉ EMPLOYEES
}

\author{
Dewi Lusita \\ Nur Pratiwi Noviati \\ Fakultas Psikologi dan Ilmu Sosial Budaya Universitas Islam Indonesia \\ Email: dewilusita31@gmail.com
}

\begin{abstract}
This study attempt to search the relationship between transformational leadership and organizational commitment of the café employees. The hypotesis tested which based on the assumption that higer transformational leadership was correlated with higer organizational commitment. A subject of 58 employees were selected for this study. Employees included server, production, managers. Data were collected by the Transformational Leadership Questionare based aspects proposed by Bass (1990) and $\alpha=0,879$ Organizational Commitment Questionare was modificaton from Allen and Meyer (1990) and $\alpha=0,884$. This study analysis used Product moment correlation by Pearson. The analysis showed that there is significant relationship between transformasional leadership and organizational commitment $p=0.004$ $(p<0.05)$. Result showed in an increasing the transformational leadership then increasing organizational commitment the employee to work. This is important to increase productivity an efficiency in an organization. Based on the results of the research, the research hypothesis is accepted.
\end{abstract}

Keywords: Transformational Leadership, Organizational Commitment, Café

\section{INTISARI}

Penelitian ini mencoba mencari hubungan antara kepemimpinan transformational dan komitmen organisasi pada karyawan kafe. Hipotesis diuji berdasarkan pada asumsi bahwa kepemimpinan transformasional yang tinggi berkorelasi dengan komitmen organinsai yang tinggi. 58 subjek karyawan dipilih untuk penelitian ini. Karyawan termasuk server, produksi, manajer. Data dikumpulkan oleh kuesioner kepemimpinan transformasional berdasarkan aspek yang disusun oleh Bass (1990) dengan $\alpha=0,879$ dan kuesioner komitmen organisasi yang dimodifikasi dari Allen dan Meyer (1990) dengan $\alpha=0,884$. Analisis penelitian ini menggunakan korelasi product moment oleh Pearson. Hasil analisis menunjukkan bahwa ada hubungan yang signifikan antara kepemimpinan transformasional dan komitmen organisasi $\mathrm{p}=0.004 \quad(\mathrm{p}<0.05)$. Hasil penelitian menunjukkan peningkatan kepemimpinan transformasional kemudian peningkatan komitmen organisasi karyawan untuk bekerja. Hal ini penting untuk meningkatkan produktivitas efisiensi dalam suatu organisasi. Berdasarkan hasil penelitian, hipotesis penelitian diterima.

Kata Kunci: Kepemimpinan Transformasional, Komitmen Organisasi, Kafe

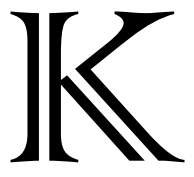

omitmen organisasi mempunyai peranan penting bagi perusahaan dalam proses operasional. Demikian juga komitmen organisasi mempunyai peranan penting bagi individu anggota suatu perusahaan untuk membangun kerjasama, memupuk semangat kerja, dan menciptakan loyalitas pada perusahaan (Suseno, 2010). Mathis dan Jackson (Sopiah, 2008) memberikan definisi bahwa komitmen organisasi merupakan derajat yang mana karyawan percaya dan menerima tujuan-tujuan organisasi dan akan tetap tinggal atau tidak 
akan meninggalkan organanisasi.

Perusahaan menginginkan pencapaian tujuan tanpa banyak mengalami kendala, diantaranya tujuan mencapai laba, memenangkan persaingan, memenuhi kepuasan pelanggan (Armansyah, 2002). Akan tetapi, permasalahan pencapaian tujuan tidak sesederhana yang dipikirkan pihak manajemen. Kendala-kendala utama yang timbul terutama dapat berasal dari para karyawan sebagai anggota organisasi, seperti rendahnya komitmen karyawan untuk tetap bekerja dalam jangka waktu yang ditentukan perusahaan (Armansyah, 2002).

Begitu juga dengan kafe $\mathrm{X}$ yang merupakan sebuah usaha kafe yang ada di Yogyakarta. Dari hasil wawancara yang dilakukan penulis terhadap karyawan kafe, terdapat indikasi bahwa komitmen yang dimiliki karyawan masih tergolong rendah. Hal ini dapat dilihat dari karyawan yang datang terlambat saat shift jaga, membolos tanpa alasan, meminta ijin tidak masuk kerja beberapa jam sebelum bekerja yang membuat beban kerja karyawan lain lebih berat jika tidak ada karyawan yang bisa menggantikan. Hal tersebut menyebabkan produktivitas kerja menurun karena seharusnya hal yang dilakukan oleh dua orang dikerjakan oleh satu orang karena tidak ada yang menggantikan tugas tersebut.

Menurut Luthans (2005) faktor penentu komitmen pada perusahaan adalah variabel-variabel (umur, masa jabatan dalam perusahaan, dan kecenderungan afeksifitas positif atau negatif, atau kontrol internal dan eksternal) dan perusahaan (desain kerja dan gaya kepemimpinan supervisor). Dari faktor-faktor yang telah disampaikan di atas, salah satu faktor penentu komitmen organisasi adalah gaya kepemimpinan transformasional yang perlu dicermati lebih lanjut.

Kepemimpinan transformasional menurut Bass (1990) terjadi ketika para pemimpin dapat memperluas dan meningkatkan kepentingan karyawan, membangkitkan kesadaran terhadap penerimaan tujuan dan misi kelompok. Kepemimpinan ini membuat karyawan lebih mengutamakan kepentingan kelompok di atas kepentingan pribadi. Pemimpin yang mampu menginspirasi bawahannya akan membuat karyawan lebih aktif dan mengeluarkan ide-ide cemerlang serta mengerahkan potensi-potensi yang dimiliki karyawan dalam bekerja. Dengan demikian, karyawan merasa diterima dan didukung terhadap apa yang dilakukannya di perusahaan sehingga membuat karyawan merasa bersemangat dan ingin tetap tinggal dan berkarir di perusahaan.

Hasil penelitian yang dilakukan oleh Popper dan Zakkai (Ariyani, 2011) menunjukkan bahwa pengaruh kepemimpinan transformasional terhadap organisasi sangat besar. Penelitian serupa yang dilakukan Rehman, Shareef, Mahmood, dan Ishaque (2012) yang menyatakan bahwa terdapat korelasi positif antara kepemimpinan transfor-masional dan kepemimpinan transaksional terhadap komitmen organisasi. Begitu juga dengan hasil penelitian Khasawneh, Omari, dan Abu Tineh (Rizadinata \& Suhariandi, 2013) yang menyimpulkan bahwa kepemimpinan transformasional digambarkan mampu 
meningkatkan komitmen organisasi karyawan.

Berdasarkan uraian di atas, maka hipotesis yang diajukan adalah ada hubungan positif antara kepemimpinan transformasional dengan komitmen organisasi pada karyawan. Semakin tinggi kepemimpinan transformasional yang diterapkan maka semakin tinggi komitmen organisasi yang dimiliki karyawan. Begitupula sebaliknya, semakin rendah kepemimpinan transformasional yang diterapkan maka semakin rendah komitmen organisasi.

\section{METODE PENELITIAN}

\section{Subjek Penelitian}

Subjek dalam penelitian ini adalah karyawan yang bekerja sebagai karyawan di kafe X di Yogyakarta yang sudah bekerja minimal enam bulan sebanyak 58 orang.

\section{Metode Pengumpulan Data}

Pengumpulan data yang diperlukan dalam penelitian ini menggunakan skala likert. Skala likert digunakan untuk mengukur sikap, pendapat, dan persepsi seseorang atau sekelompok orang tentang fenomena sosial (Sugiyono, 2008). Dalam penelitian, fenomena sosial ini telah ditetapkan secara spesifik oleh peneliti yang selanjutnya disebut sebagai variabel penelitian (Sugiyono, 2008). Melalui skala likert, variabel yang akan diukur dijabarkan menjadi indikator variabel. Kemudian indikator tersebut dijadikan sebagai titik tolak untuk menyusun item-item instrumen yang dapat berupa pernyataan atau pertanyaan (Sugiyono, 2008).
1. Kepemimpinan Transformasional

Alat ukur yang dipakai untuk mengukur kepemimpinan merupakan alat ukur yang dibuat sendiri oleh peneliti yang disusun berdasarkan aspek-aspek kepemimpinan transformasional yang diungkapkan oleh Bass (1990). Skala ini terdiri dari lima alternatif jawaban, yaitu Sangat Setuju (SS), Setuju (S), Tidak Setuju (TS) dan Sangat Tidak Setuju (STS). Penilaian tiap alternatif jawaban bergerak dari angka 1 sampai 4. Pada setiap aitem favorable (arah item yang isinya mendukung, memihak, atau menunjukan ciri atribut yang diukur), nilai 4 diberikan pada jawaban Sangat Setuju (SS) dan nilai 1 diberikan pada jawaban Sangat Tidak Setuju (STS).

2. Komitmen Organisasi

Pengukuran komitmen berdasar skala komitmen organisasi yang mencakup skala affective commitment, continuance commitment, dan normative commitment yang dimodifikasi oleh peneliti berdasarkan aspek-aspek komitmen organisasi yang diungkapkan oleh Allen dan Meyer (Muafi, 2008). Alat ukur yang dibuat disesuaikan dengan kondisi tempat penelitian.

Jumlah aitem dalam skala ini adalah 45 aitem. Subyek diminta untuk merespon pernyataan-pernyataan yang diajukan dengan memilih salah satu dari empat macam pilihan yang diajukan yaitu Sangat Sesuai (SS), Sesuai (S), Tidak Sesuai (TS), Sangat Tidak Sesuai (STS) untuk aitem favorable maka jawaban SS diberi skor 4, jawaban S diberi skor 3, jawaban TS diberi skor 2, jawaban STS diberi skor 1. Sedangkan untuk unfavorable maka jawanan SS diberi skor 1, jawaban S diberi 
skor 2, jawaban TS diberi skor 3, dan diberi skor 4 untuk jawaban STS.

\section{Metode Analisis Data}

Analisis data secara kuantitatif menggunakan metode analisis statistik. Pengujian korelasi dari kedua variabel penelitian yaitu hubungan antara gaya kepemimpinan transformasional terhadap komitmen organisasi karyawan menggunakan korelasi product moment dari Pearson. Sedangkan keseluruhan komputasi data dilakukan menggunakan SPSS (Statistical Program for Social Science).

\section{HASIL PENELITIAN}

Deskripsi data penelitian bertujuan untuk mengetahui tinggi atau rendahnya tingkat komitmen organisasi dan kepemimpinan transformasional pada karyawan kafe $\mathrm{X}$, yaitu karyawan yang menjadi subjek penelitian. Deskripsi data subjek penelitian secara umum adalah sebagai berikut :

Tabel 1. Deskripsi Data Penelitian

\begin{tabular}{ccccccccc}
\hline & \multicolumn{4}{c}{ Hipotetik } & \multicolumn{5}{c}{ Empirik } \\
\cline { 2 - 8 } Variabel & $\begin{array}{c}\mathbf{X} \\
\mathbf{m i n}\end{array}$ & $\mathbf{X}$ max & Mean & SD & $\begin{array}{c}\mathbf{X} \\
\boldsymbol{m i n}\end{array}$ & $\mathbf{X}$ max & Mean & SD \\
\hline $\begin{array}{c}\text { Komitmen } \\
\text { Organisasi } \\
\text { Kepemimpinan } \\
\text { Transformasional }\end{array}$ & 26 & 104 & 65 & 13 & 57 & 90 & 73.05 & 7.16 \\
\hline
\end{tabular}

Tabel 2. Kategorisasi Variabel Komitmen Organisasi

\begin{tabular}{lccc}
\hline \multicolumn{1}{c}{ Kategori } & Skor & Jumlah & Persentase \\
\hline Sangat Tinggi & $\mathrm{X}>88.4$ & 1 & $1.73 \%$ \\
Tinggi & $72.8 \leq \mathrm{X} \leq 88.4$ & 26 & $44.82 \%$ \\
Sedang & $57.2 \leq \mathrm{X}<72.8$ & 30 & $51.72 \%$ \\
Rendah & $41.6 \leq \mathrm{X}<57.2$ & 1 & $1.73 \%$ \\
Sangat Rendah & $\mathrm{X}<41.6$ & 0 & $0 \%$ \\
\hline Jumlah & & $\mathbf{5 8}$ & $\mathbf{1 0 0 . 0 0 \%}$ \\
\hline
\end{tabular}

Tabel 3. Kategorisasi Variabel Kepemimpinan Transformsional

\begin{tabular}{lccc}
\hline Kategori & Skor & Frekuensi & Persentase \\
\hline Sangat Tinggi & $\mathrm{X}>81.6$ & 10 & $17.24 \%$ \\
Tinggi & $62.7 \leq \mathrm{X} \leq 81.6$ & 39 & $67.24 \%$ \\
Sedang & $52.8 \leq \mathrm{X}<67.2$ & 9 & $15.52 \%$ \\
Rendah & $38.4 \leq \mathrm{X}<52.8$ & 0 & $0 \%$ \\
Sangat Rendah & $\mathrm{X}<38.4$ & 0 & $0 \%$ \\
\hline Jumlah & & $\mathbf{5 8}$ & $\mathbf{1 0 0 . 0 0 \%}$ \\
\hline
\end{tabular}


Dari hasil kategorisasi di atas dapat disimpulkan bahwa komitmen organisasi pada karyawan $\mathrm{X}$ dengan presentase paling tinggi berada pada kategori sedang (51.72 $\%)$. Rentang skor pada kategori sedang adalah $57.2 \leq \mathrm{X}<$ 72.8. Sedangkan kepemimpinan transformasional dengan presentase paling tinggi berada pada kategori tinggi (67.24\%). Rentang skor pada kategori tinggi adalah $62.7 \leq \mathrm{X} \leq 81.6$.

\section{Uji Asumsi}

Sebelum melakukan analisis data, terlebih dahulu dilakukan uji asumsi yang meliputi uji normalitas dan uji linieritas.

1. Uji Normalitas

Pengujian normalitas dilakukan terhadap distribusi skor perilaku seksual dan pengetahuan tentang kesehatan reproduksi dengan menggunakan teknik One-Sample Kolmogorov-Smirnov Test pada SPSS. Berdasarkan hasil pengolahan data pada variabel komitmen organisasi, diperoleh $(\mathrm{K}-\mathrm{SZ})=0.74$ dengan $\mathrm{p}=0.640$ $(p>0.05)$. Hasil pengolahan data untuk variabel kepemimpinan transformasional diperoleh $(\mathrm{K}-\mathrm{SZ})=1.25$ dengan $\mathrm{p}=0.08$ ( $>0.05)$. Hasil menunjukkan bahwa data normal.

\section{Uji Linieritas}

Hasil pengolahan data menunjukkan nilai $\mathrm{F}=5.64$ dengan $\mathrm{p}=0.01$. Hasil analisis tersebut menunjukkan bahwa hubungan antara kepemimpinan transformasional dengan komitmen organisasi memenuhi asumsi linearitas atau mengikuti satu garis lurus.

\section{Uji Hipotesis}

Uji hipotesis dilakukan untuk mengetahui hubungan antara kedua variabel. Uji hipotesis dilakukan dengan menggunakan teknik product moment dari Pearson dengan menggunakan program komputer Statistical Package for the Social Sciences (SPSS). Hasil analisis data menunjukkan korelasi antara variabel kepemimpinan transformasional terhadap komitmen organisasi $(\mathrm{r}=0.34$ dengan $\mathrm{p}=$ $0.004(\mathrm{p}<0.05)$. Hal ini menunjukan bahwa hipotesis yang diajukan diterima.

Tabel 4. Korelasi antara Komitmen Organisasi dan Kepemimpinan Transformasional

\begin{tabular}{lcc}
\hline \multicolumn{1}{c}{ Variabel } & $\mathrm{r}$ & $\mathrm{r}^{2}$ \\
\hline Organizational Commitment * Transformational & $0.34^{*}$ & 0.004 \\
Leadership & & \\
\hline
\end{tabular}

*Signifikan pada level 0.05 (1-tailed)

\section{Analisis Tambahan}

Analisis tambahan pada penelitian ini adalah melakukan uji regresi dan uji beda. Analisis tambahan dilakukan agar dapat menganalisis data penelitian dengan lebih mendetail dan mendalam. Uji regresi bertujuan untuk mengetahui aspek-aspek kepemimpinan transformasional yang berkontribusi terhadap komitmen organisasi. Penghitungan uji regresi menggunakan Regresi Linear dan metode yang digunakan yaitu Stepwise. Berdasarkan uji regresi, diketahui bahwa hanya aspek karisma yang berkontribusi terhadap komitmen organi- 
sasi. Hal ini mengartikan bahwa aspek kepemimpinan berkontribusi sebesar 11\% terhadap komitmen karyawan dengan $\mathrm{p}=$ $0.01(\mathrm{p}<0.05)$.

Menurut hasil analisis hasil uji hipotesis korelasional berdasarkan jenis kelamin menunjukkan bahwa subjek lakilaki memiliki komitmen yang lebih tinggi dibandingkan subjek perempuan dengan aspek yang paling mempengaruhi adalah aspek karisma dengan nilai $r=0.551$ dan $p$ $=0.001$. Analisis berdasarkan rentang usia menunjukkan bahwa subjek dengan rentang usia 15-20 tahun memiliki komitmen yang lebih tinggi dibandingkan subjek rentang usia 21-25 tahun dengan aspek yang paling mempengaruhi adalah aspek karisma dengan nilai $r=0.414$ dan $p$ $=0.014$. Analisis berdasarkan jabatan menunjukkan bahwa subjek dengan jabatan produksi memiliki komitmen yang lebih tinggi dibandingkan subjek jabatan server dan kapten dengan aspek yang paling mempengaruhi adalah aspek karisma, nilai $r=0.56$ dan $p=0.001$.

\section{PEMBAHASAN}

Penelitian yang bertujuan untuk mengetahui hubungan antara kepemimpinan transformasional dengan komitmen organisasi pada seluruh karyawan kafe $\mathrm{X}$ yang berjumlah 58 orang menemukan bahwa ada hubungan yang signifikan antara kepemimpinan transformasional dengan komitmen organisasi. Hubungan antara kedua variabel ini menunjukkan bahwa semakin tinggi tingkat kepemimpinan transformasional, maka semakin tinggi komitmen karyawan. Sebaliknya, semakin rendah tingkat kepemimpinan transformasional, maka semakin rendah komitmen karyawan. Penelitian menunjukkan bahwa hipotesis yang diajukan oleh peneliti dapat diterima.

Adanya hubungan antara kepemimpinan transformasional dengan komitmen karyawan menggambarkan bahwa gaya kepemimpinan ini mampu meningkatkan komitmen karyawan terhadap perusahaan. Pemimpin yang mampu membuat karyawan percaya kepada dirinya membuat karyawan merasa bahwa pemimpin tersebut akan mampu membawa dirinya kepada hal-hal yang memajukan dirinya dan organisasi. Pemimpin yang dirasa memberikan perhatian, bantuan dan menginspirasi bagi karyawan membuat karyawan merasa dirinya termotivasi ketika bekerja dan mengupayakan segenap kemampuannya dalam menjalankan tugasnya. Karyawan tersebut juga bersedia memberikan ide-ide kreatif dan inovatif untuk memajukan perusahaan tempatnya bekerja.

Hasil penelitian menunjukkan bahwa sumbangan efektif kepemimpinan transformasional terhadap komitmen organisasi pada karyawan sebesar 0.11 . Hal tersebut menggambarkan bahwa kepemimpinan transformasional memberikan pengaruh sebesar $11 \%$ terhadap komitmen organisasi pada karyawan kafe X. Sedangkan sisanya dipengaruhi oleh faktor-faktor lain yang tidak terlibat dalam penelitian ini. Variabel kepemimpinan transformasional bukanlah satu-satunya faktor yang mempengaruhi komitmen organisasi pada karyawan. Menurut Luthans (2005) terdapat faktor lain yang mempengaruhi 
komitmen karyawan yaitu umur, masa jabatan dalam perusahaan, dan kecenderungan afeksifitas positif atau negatif, atau kontrol internal dan eksternal, desain kerja dan sebagainya.

Hasil penelitian ini menunjukkan adanya keselarasan dengan pendapat Bass (Budiarto \& Selly, 2004) yang mengatakan bahwa pemimpin transformasional memiliki kemampuan uuntuk menciptakan komitmen yang tinggi pada karyawannya. Penelitian Rehman, dkk (2012) dengan judul Perceived Leadership Styles and Organizational Commitment yang dilakukan di Pakistan juga menunjukkan bahwa baik kepemimpinan transaksional dan kepemimpinan transformasional memiliki hubungan positif dengan komitmen organisasi. Selain itu, penelitian Rizadinata dan Suhariandi (2013) yang bertujuan untuk mengetahui hubungan antara kepemimpinan transformasional dengan komitmen organisasi pada karyawan divisi produksi PT Gunawan Dianjaya Stell Surabaya menemukan bahwa terdapat hubungan yang signifikan antara kepemimpinan transformasional dengan komitmen organisasi. Beberapa penelitian di atas sejalan dengan hasil penelitian ini yang menunjukkan bahwa terdapat hubungan antara kepemimpinan transformasional dengan komitmen organisasi.

Komitmen karyawan, baik yang tinggi maupun yang rendah akan berdampak terhadap karyawan dan organisasi. Pada karyawan, komitmen organisasi akan mempengaruhi pengembangan karir karyawan di organisasi. Sedangkan pada organisasi, karyawan yang memiliki komitmen tinggi akan menimbulkan kinerja organisasi yang tinggi, tingkat absensi berkurang, loyalitas karyawan, dan lain sebagainya (Sopiah, 2008).

Penelitian ini secara keseluruhan memiliki kelemahan. Pertama, peneliti tidak memfasilitasi subjek yang ingin memilih jawaban netral, namun hal tersebut dapat diatasi dengan memberi penjelasan kepada subjek untuk memilih jawaban yang cenderung lebih dirasakan oleh subjek pada suatu kondisi (dalam pernyataan) dengan kenyataan. Kedua, kurangnya keterlibatan peneliti pada saat subjek mengisi kuesioner membuat sebagian subjek yang kurang memahami maksud peneliti memberikan respon yang tidak sesuai dengan kenyataan.

\section{SIMPULAN DAN SARAN}

\section{Simpulan}

Berdasarkan hasil analisis data dan pembahasan yang dilakukan sebelumnya, disimpulkan bahwa ada hubungan yang signifikan kepemimpinan transformasional dengan komitmen organisasi pada karyawan kafe X. Hal tersebut menunjukkan bahwa hipotesis yang mengatakan bahwa terdapat hubungan antara kepemimpinan transformasional dengan komitmen karyawan kafe $\mathrm{X}$ dapat diterima

\section{Saran}

1. Saran kepada karyawan

Bagi karyawan kafe $\mathrm{X}$ hendaknya dapat menjaga dan meningkatkan komitmen yang dimiliki, hal tersebut dilakukan supaya dapat memajukan kafe X. Upaya yang dapat dilakukan ialah karyawan ikut terlibat dalam memberikan 
ide-ide untuk kemajuan kafe X. Karyawan juga diharapkan mengembangkan kreativitas dan memberikan inovasi kepada kafe $\mathrm{X}$ agar dapat bertahan dan menjadi lebih berkembang dan mampu bersaing dengan kafe-kafe lain di Yogyakarta.

\section{Saran kepada pihak kafe $\mathrm{X}$}

Berdasarkan hasil penelitian ini, saran yang dapat diberikan dan memungkinkan untuk dipertimbangkan bagi kafe $\mathrm{X}$ adalah disarankan agar pihak kafe $\mathrm{X}$ dapat memberikan kesempatan kepada para karyawan untuk berperan aktif dan menunjukkan eksistensinya dalam melakukan tujuan-tujuan organisasi. Pihak perusahaan juga dapat memberikan coaching atau mentoring kepada masingmasing karyawan untuk melakukan pendampingan serta membantu masalahmasalah pekerjaan yang dihadapi karyawan.

\section{Saran kepada Peneliti Selanjutnya}

Bagi peneliti selanjutnya yang ingin mengambil topik mengenai kepemimpinan transformasional terhadap komitmen organisasi khususnya di kafe $\mathrm{X}$ disarankan menggali lebih dalam permasalahan yang terjadi di kafe $\mathrm{X}$ melalui wawancara mendalam. Selanjutnya, peneliti yang menggunakan metode penelitian kuantitatif disarankan untuk memfasilitasi jawaban netral pada alternatif jawaban alat ukur. Peneliti selanjutnya juga lebih memperhatikan status karyawan sebagai karyawan kontrak dan mencari aspek yang lebih sesuai dengan konsep komitmen organisasi. Keterlibatan sepenuhnya juga dirasa perlu agar subjek yang kurang mengerti dengan pertanyaan penelitian dapat langsung bertanya.

\section{DAFTAR PUSTAKA}

Allen, N.J., \& Meyer, J.P. (1990). The measurement and antecedents of affective, continuance, and normative commitment to organization. Journal of occupational psychology, 63, 1-18.

Ariyani, V. (2011). Pengaruh Kepemimpinan Transformasional terhadap Motivasi Kerja Dosen Pada Universitas yang Berada di Kota Madiun. Jurnal Widya Warta, (01).

Armansyah. (2002). Komitmen organisasi dan imbalan finansial. Jurnal Ilmiah Manajemen \& Bisnis, 02 (02).

Bass, B.M. (1990). From transactional to transformasional leadership: learning to share the vision. Organizational Dynamics, 18 (3), 9-31.

Budiarto, Y., \& Selly. (2004). Komitmen karyawan pada perusahaan ditinjau dari kepemimpinan transformasional dan transaksional. Jurnal Psikologi, 2 (2).

Luthans, F. (2005). Perilaku organisasi. (Edisi 10). Yogyakarta: Andi Ofsett.

Muafi. (2008). Perilaku organisasional. (Rev. ed.). Yogyakarta: Wimaya Press.

Rehman, S.U., Shareef, A., Mahmood, A., \& Ishaque, A. (2012). Perceived 
leadership styles and organizational commitment. Interdiciplinary Journal of Contemporary Research In Bussiness, 2, 1.

Rizadinata \& Suhariyandi, F. (2013). Hubungan antara kepemimpinan transformasional dengan komitmen organisasi pada karyawan divisi produksi PT. Gunawan Dianjaya Steel Surabaya. Jurnal Psikologi Industri dan Organisasi, 02, 1.
Sopiah. (2008). Perilaku organisasi. Yogyakarta: Andi Offset.

Sugiyono. (2008). Metode penelitian kuantitatif, kualitatif dan $R \& D$. Bandung: Alfabeta.

Suseno, M.N. (2010). Pengaruh dukungan sosial dan kepemimpinan transformasional terhadap komitmen organisasi dengan mediator motivasi kerja. Jurnal Psikologi, 37 (1), 94-109. 